\title{
Morphology of Right Atrioventricular Valve Annulus and Leaflets in Autopsy Specimens
}

\author{
Raniprabha Sukumaran ${ }^{1}$, Maheswary Thampi Santhakumary² \\ ${ }^{1}$ Assistant Professor, Department of Anatomy, Government Medical College, Kottayam, Kerala, India. \\ ${ }^{2}$ Associate Professor, Department of Anatomy, Government Medical College, Kottayam, Kerala, India.
}

\section{ABSTRACT}

\section{BACKGROUND}

Most tricuspid valve conditions are mechanical problems that will require surgery like valve repair and valve replacement. The proper size of the valve prosthesis and the size of the annuloplasty band are determined by the measurements of the valve annulus and leaflets. The present study is aimed to provide normal measurements of the tricuspid valve that would help cardiac surgeons in proper planning and execution of tricuspid valve surgeries.

\section{METHODS}

This descriptive study was conducted in 60 adult human hearts of both sexes during medico legal autopsy in the Department of Forensic Medicine, GMC Kottayam from November 2018 to April 2019. The heart specimens, free from any pathology, variation, were dissected. The diameter, circumference of the annulus and the length and height of the leaflets were measured. The range, mean, standard deviation and coefficient of variation of each parameter were calculated.

\section{RESULTS}

In the present study, the circumference of the tricuspid valve measured $11.65+/-1.28$ cms. Diameter was recorded as $4.4+/-0.73 \mathrm{cms}$. The anterior leaflet was the largest in size while the posterior leaflet was the smallest. The length of the base of the leaflets was $4.59+/-1.15 \mathrm{~cm}, 2.86+/-1 \mathrm{cms}$ and $4.23+/-0.94 \mathrm{cms}$ for anterior, posterior and septal leaflet respectively. The mean height of the leaflets was $2.03 \mathrm{cms}$, $1.505 \mathrm{cms}$ and $1.667 \mathrm{cms}$ for anterior, posterior and septal leaflet respectively.

\section{CONCLUSIONS}

The normal data on morphometric parameters of the tricuspid valve will help cardiovascular surgeons. It also helps in the designing and manufacture of prosthetic heart valves and annuloplasy rings.

\section{KEY WORDS}

Tricuspid Valve Complex, Annulus, Leaflets, Circumference, Diameter, Length of Leaflets, Annuloplasty, Prosthetic Valve
Corresponding Author:

Dr. Maheswary Thampi Santhakumary,

Associate Professor,

Department of Anatomy,

Government Medical College,

Kottayam, Kerala, India.

E-mail:drsmthampi@gmail.com

DOI: $10.14260 /$ jemds $/ 2019 / 552$

Financial or Other Competing Interests: None.

How to Cite This Article:

Sukumaran $R$, Santhakumary MT. Morphology of right atrioventricular valve annulus and leaflets in autopsy specimens. J. Evolution Med. Dent. Sci. 2019;8(32): 2534-2538 DOI: 


\section{BACKGROUND}

The right atrioventricular valve or tricuspid valve consists of the right atrioventricular orifice and its associated annulus, the leaflets, chordae tendineae and papillary muscles ${ }^{1}$. The Tricuspid valve is of great clinical importance in the light of progress in cardiac surgery. Most tricuspid valve conditions are mechanical problems that will eventually require surgery to reduce symptoms and the risk of complications. Tricuspid regurgitation occurs mainly from tricuspid annular dilation. It can result from left sided heart failure from myocardial or valvular causes, right ventricular volume and pressure overload or dilation of cardiac chambers. ${ }^{2}$ The current treatment strategy is to repair the dilated tricuspid annulus at the time of mitral valve surgery ${ }^{3}$ The tricuspid valve repair or valve replacement are procedures that treat diseases affecting the valve. Annuloplasty band insertion is the repair procedure done to reduce the size of tricuspid valve annulus. The area of the anterior leaflet or the length of the base of the septal leaflet (Inter trigonal distance) may be used to determine the appropriate size of the band. The size of the valve prosthesis is determined by the diameter of the valve. ${ }^{4}$ These repair procedures help to achieve coaptation. The valve does not lie in a single plane. In a study done by Fukuda et al healthy subjects had elliptical shaped tricuspid annulus, with the posteroseptal portion being the lowest and the anteroseptal portion the highest. ${ }^{5}$ Its position and structural complexity adds to the challenges in its assessment by radiological techniques in living human beings. ${ }^{6}$ It is not possible to visualize all the cusps simultaneously in one cross sectional view by standard transthoracic two dimensional echocardiography. Most currently available annuloplasty rings are essentially planar. Therefore, an optimally shaped annuloplasty ring needs to be designed that mimics the normal structure of the annulus. Detailed study of the valve will be helpful for cardiovascular surgeons during surgical procedures. However, only very few such studies in Indian population are available in literature. The aim of the present study is to describe the morphology of leaflets, annulus by measuring the circumference, diameter of the annulus, length and height of each leaflet.

\section{METHODS}

This descriptive study was conducted in 60 adult human hearts of both sexes during medicolegal autopsy in the Department of Forensic Medicine, GMC Kottayam. The study period was 6 months from November 2018 to April 2019. The heart specimens from autopsies performed within 18 hours of death were included in the study. The morphology of the heart valve is not altered by putrefaction by that time. The hearts which were injured before or during autopsy, diseased, burnt or decomposed were not included in the study.

The heart specimens were cleaned and cleared of any clots within the chambers. The first incision was given from right aspect of inferior vena cava to the superior vena cava. The right atrium was opened. Then the right atrium was incised staying about $1 \mathrm{~cm}$ above the tricuspid valve annulus. Circumference and diameter of the valve annulus were measured. The diameter was measured from the anteroseptal commissure to the exactly opposite point of valve on the acute margin of the heart. The number of leaflets was noted.

The second incision was given along the inferior border of the heart up to the lower end of anterior interventricular groove. The third incision was given just to the right of anterior interventricular groove. The valve was then opened by cutting through the annulus at the junction of anterior and posterior leaflets. The length of each leaflet at its base and the height at its center, from free margin to base, were measured. All measurements were made by using non-stretchable black silk thread. This was subsequently straightened, and the length was measured by the metric ruler with least readability of 0.5 $\mathrm{mm}$. As per Rusted et al, this measurement technique has a measurement error of no more than $0.2-0.3 \mathrm{~mm}$. The observations were recorded. Photographs were taken using digital camera.

\section{Statistical Analysis}

After collecting the data from all the samples, data analysis was done with trial version of SPSS software. The Range, Mean, Standard Deviation \& Coefficient of variation of each parameter was calculated. The results were compared with previous studies.

\section{RESULTS}

\begin{tabular}{|c|c|c|c|c|c|c|c|c|c|}
\hline & & Circumferenc & iameter & A L & P L & S L & AH & $\mathbf{P H}$ & SH \\
\hline \multirow{2}{*}{$\mathbf{N}$} & Valid & \begin{tabular}{|l|}
60 \\
\end{tabular} & \begin{tabular}{|l|l}
60 \\
\end{tabular} & 60 & 60 & 60 & 60 & 60 & 60 \\
\hline & Missing & $\mathbf{0}$ & $\mathbf{0}$ & $\mathbf{0}$ & $\mathbf{0}$ & $\mathbf{0}$ & $\mathbf{0}$ & $\mathbf{0}$ & $\mathbf{0}$ \\
\hline \multicolumn{2}{|c|}{ Mean } & 11.655 & 4.400 & 4.597 & 2.862 & 4.237 & 2.030 & 1.505 & 1.667 \\
\hline \multicolumn{2}{|c|}{ Median } & 11.500 & 4.450 & 4.500 & 2.600 & 4.050 & 2.000 & 1.500 & 1.700 \\
\hline \multicolumn{2}{|c|}{ Std. Deviation } & 1.2786 & .7307 & 1.1519 & 1.0206 & 9435 & 5169 & .6302 & .5962 \\
\hline \multicolumn{2}{|c|}{ Range } & 5.3 & 3.8 & 5.8 & 4.3 & 4.5 & 1.9 & 2.2 & 2.2 \\
\hline \multicolumn{2}{|c|}{ Minimum } & 9.5 & 2.7 & 1.6 & 1.0 & 2.0 & 1.1 & .5 & .6 \\
\hline \multicolumn{2}{|c|}{ Maximum } & 14.8 & 6.5 & 7.4 & 5.3 & 6.5 & 3.0 & 2.7 & 2.8 \\
\hline \multirow{3}{*}{ Percentiles } & 25 & 10.500 & 3.850 & 3.713 & 2.025 & 3.600 & 1.525 & 1.000 & 1.125 \\
\hline & 50 & 11.500 & 4.450 & 4.500 & 2.600 & 4.050 & 2.000 & 1.500 & 1.700 \\
\hline & 75 & 12.500 & 4.675 & 5.300 & 3.500 & 5.000 & 2.475 & 2.000 & 2.100 \\
\hline \multicolumn{10}{|c|}{$\begin{array}{l}\text { AL -Length of anterior leaflet, A H - Height of anterior leaflet. PL- Length of posterior } \\
\text { leaflet. PH- Height of posterior leaflet. SL- Length of septal leaflet. SH- Height of septal } \\
\text { leaflet. }\end{array}$} \\
\hline \multicolumn{10}{|c|}{$\begin{array}{c}\text { Table 1. Showing Range, Mean and Standard Deviation } \\
\text { of each Parameter Measured }\end{array}$} \\
\hline
\end{tabular}

\begin{tabular}{|c|c|}
\hline Parameter & Coefficient of Variation \\
\hline Diameter of valve & 16.6 \\
\hline Circumference of the valve & 10.97 \\
\hline Length of anterior leaflet & 25 \\
\hline Length of septal leaflet & 22.2 \\
\hline Length of posterior leaflet & 35.6 \\
\hline Height of anterior leaflet & 25.4 \\
\hline Height of septal leaflet & 35.7 \\
\hline Height of posterior leaflet & 41.8 \\
\hline Table 2. Showing Coefficient of Variation of each Parameter \\
Expressed as a Percentage (\%).
\end{tabular}

\section{DISCUSSION}

It is axiomatic that a thorough knowledge of valvar anatomy is a prerequisite for successful surgery, be it valvar replacement or reconstruction. All the components of the valvar complex must work in harmony so as to achieve valvar competence. ${ }^{7}$ The right atrioventricular valve anatomy including its annulus, three leaflets or cusps, chordal apparatus and papillary muscles is unique to each individual. The Tricuspid annulus is 
a collagenous ring succeeding the orifice. The bases of the leaflets are attached to the annulus. It is composed of a pair of curved,tapered subendocardial tendons known as fila coronaria which extend from the right fibrous trigone component of central fibrous body. They partly encircle the circumference of the valve. Inferolaterally, the tips of the fila are connected by more tenuous, deformable fibroblastic sulcal aroelar tissue. ${ }^{8}$

Traditionally the valve has been described as having three leaflets; anterior, inferior/ posterior, and septal separated by three major commissures. The leaflets are arranged to lie against the three walls of the right ventricle; anterior, inferior and septal respectively. The commissures are named as the anteroseptal, postero septal and anteroposterior commissures. The edges and ventricular surfaces of the leaflets receive the attachments of chordae tendineae arising from the apex of papillary muscles. Fan shaped chordae are attached to the commissures. Usually the large anterior papillary muscle is connected by chordae to anterior and posterior cusps. A small posterior papillary muscle is attached to posterior and septal cusps. Several small septal papillary muscles join the septal and anterior cusps. ${ }^{9}$

\section{Circumference}

In the present study, the mean circumference of tricuspid valve was found to be $11.65 \mathrm{~cm}$. The tricuspid valve orifice is best seen from the atrial aspect. It is somewhat oval or circular in outline, depending upon the phase of the cardiac cycle. It measures on an average $11.4 \mathrm{~cm}$ in circumference in males and $10.8 \mathrm{~cm}$ in females. It is oriented almost vertically making an angle of $45^{\circ}$ with the sagittal plane. The orifice faces downwards forwards and to the left towards the ventricular apex. ${ }^{10}$

\begin{tabular}{|l|c|c|c|c|c|c|c|}
\hline Ta & Table: 1 Showing Circumference of Tricuspid Valve from the Present \\
Study and some Previous Studies \\
\hline
\end{tabular}

\section{Diameter}

Diameter of the valve was found to be $4.4+/{ }_{-} 0.73 \mathrm{~cm}$ in our study. In the study done by Westaby et al the overall diameter of $3.64+/-0.44 \mathrm{~cm} .{ }^{11}$ SairanenH, LouhimoI et al ${ }^{17}$ and Anwar ${ }^{18}$ et al have reported that the Tricuspid annular diameter and dimensions of the valve orifice closely correlated with age,body weight, height and body surface area. This partly explains the smaller Tricuspid valve and its dimensions in shorter and smaller sized individuals.

\section{Length of leaflets}

\begin{tabular}{|c|c|c|c|c|}
\hline $\begin{array}{c}\text { Length } \\
\text { (cm) }\end{array}$ & $\begin{array}{c}\text { Present } \\
\text { Study }\end{array}$ & Kalyani12 $^{\text {12 }}$ & Motabagani $^{13}$ & Silver $^{\mathbf{1 4}}$ \\
\hline $\begin{array}{c}\text { Anterior } \\
\text { cusp }\end{array}$ & $3.4-5.7$ & $3.94-5.1$ & $4-4.7$ & $3.1-4.7$ \\
\hline Septal cusp & $3.2-5$ & $3.35-4.1$ & $2.99-3.65$ & $2.9-4.5$ \\
\hline $\begin{array}{c}\text { Posterior } \\
\text { cusp }\end{array}$ & $1.8-3.89$ & $2.65-3$ & $2.64-3.2$ & $2.9-4.5$ \\
\hline \multicolumn{6}{|c|}{ Table 2. Showing Length of Leaflets of Tricuspid Valve from Present } \\
Study and Some Previous Studies \\
\hline
\end{tabular}

In our study, the anterior leaflet of the Tricuspid valve was the largest in length,the posterior leaflet was the smallest in length. Most of the studies in literature mention that the anterior cusp is the largest in length. The values obtained for the mean length of anterior cusp, septal cusp and posterior cusp were $4.597 \mathrm{~cm}, 4.237 \mathrm{~cm}$ and $2.86 \mathrm{~cm}$ respectively. The attachments of the valve leaflets to the annulus are at different levels.. The highest part is at the anteroseptal commissure near the midpoint of the membranous interventricular septum.. From the highest point the attachment of the anterior leaflet gradually slopes down to the anteroposterior commissure. The attachments of both the posterior leaflet and the posteroseptal half of the septal leaflet are roughly horizontal and about $15 \mathrm{~mm}$ lower than the highest part of the valve`s attachment. From about the midpoint of the septal leaflet, the attachment angles upwards at about $30^{\circ}$ from the horizontal to reach the anteroseptal commissure. ${ }^{14}$

\section{Height of Leaflets}

\begin{tabular}{|c|c|c|c|}
\hline Height (cm) & Present Study & Silver ${ }^{\mathbf{4}}$ & Aarti Rohilla $^{\mathbf{9}}$ \\
\hline Anterior cusp & $1.5-2.54$ & $2-2.8$ & $1.68-2.16$ \\
\hline Septal cusp & $1.07-2.26$ & $1.4-2$ & $1.23-1.82$ \\
\hline Posterior cusp & $0.87-2.13$ & $1.5-2.1$ & $1.33-1.9$ \\
\hline Table 3. Showing Height of Leaflets of Tricuspid Valve from Present \\
Study and Some Previous Studies \\
\hline
\end{tabular}

The maximum average height measured in the present study for anterior leaflet. The minimum was for posterior cusp. The mean height of anterior cusp, septal cusp, and posterior cusp were $2.03 \mathrm{~cm}, 1.667 \mathrm{~cm}$ and 1.505 respectively. The annulus of the tricuspid valve is thinner and more difficult to identify during surgery than that of mitral valve. Cardiovascular surgeons must take care while suturing the annulus to avoid iatrogenic injury to AV node, AV nodal artery, membraneous septum and Bundle of His. AV node lies in the atrial septum bordering the septal leaflet, Membranous interventricular septum lies beneath the septal leaflet inferior to anteroseptal commissure. Bundle of His penetrates the right trigone under the membanous septum approximately $5 \mathrm{~mm}$ inferior to the anteroseptal commissure. Non coronary cusp of aortic valve also lies near the anteroseptal commissure. The right coronary artery runs anterior to the anterior leaflet annulus and may be injured by deep sutures in the annulus. ${ }^{20}$

The most common indication for surgical intervention on the Tricuspid valve is functional or secondary Tricuspid regurgitation. That means regurgitation developing in patients with normal tricuspid valve leaflets as a result of right ventricular dysfunction and tricuspid annular dilation. It occurs frequently in patients with advanced Mitral valve disease and Pulmonary hypertension. ${ }^{21}$ Pulmonary hypertension leads to elevation of right ventricular systolic and diastolic pressures, ventricular cavity enlargement and annular dilation. Rheumatic fever continues to be the most common cause of organic Tricuspid valve disease. ${ }^{22}$ Rheumatic tricuspid involvement typically co-exists with mitral or aortic valve disease. ${ }^{23}$ The circumference of the tricuspid annulus lengthens primarily along the attachments of the anterior and posterior leaflets. ${ }^{24}$ The posterior annulus of the tricuspid valve is the only structurally unsupported area of the valve annulus, making this area particularly susceptible to dilatation and subsequent tricuspid regurgitation. In bicuspidization sutures are put to obliterate the annular segment corresponding to the posterior leaflet. The septal leaflet 
portion on the other hand, is fixed between the right and left trigones and the atrial and ventricular septa preventing its lengthening. ${ }^{25}$ Because of this, tricuspid annular sizing algorithms have been based on the dimension of the base of the septal leaflet. ${ }^{26}$ As annular dilation progress, the chordal papillary muscle complex becomes functionally shortened, although it remains normal in appearance. This prevents leaflet coaptation and leads to valvular incompetence.

Previously it was thought that functional tricuspid regurgitation decreases or even disappears after surgical correction of left sided valve disease. ${ }^{27}$ However, further studies show that functional TR may progress even after left sided surgery. The current approach is to perform an annuloplasty in patients with dilated annulus or $>$ mild TR. ${ }^{28}$ The 2006 American Heart Association valve guidelines recommend tricuspid valve repair for patients with a transverse annular diameter (Measured between AS and PS commissures) of $70 \mathrm{~mm}$. According to Sellke and Ruel, tricuspid annular diameter $50 \mathrm{~mm}$ or more is to be repaired even when there is no associated TR, in patients undergoing mitral valve surgery. 4

Annuloplasty involves the tightening of the annulus by implanting an artificial ring. According to Grover and Mack, the proper size of the Tricuspid valve ring is detemined by the size of the anterior leaflet of the valve and the amount of tethering of the leaflet. ${ }^{29}$ According to Sellke and Ruel, the area of the anterior leaflet or the length of the base of the septal leaflet may be used to determine the appropriate size of the annuloplasty ring. ${ }^{4}$ Tricuspid rings are designed with an opening that corresponds to the region of the atrioventricular node to minimize the chance of incurring damage to the conducting system during surgery. The ring size is determined by the length of the fibrous septal annulus between commissures along the septal leaflet, with a goal of slight undersizing. ${ }^{30}$ According to David, Luca et al a sizer is used to measure the area of the septal leaflet to allow the selection of the ring. ${ }^{20}$ When the severity of the valvular distortion prevents a satisfactory repair procedure, valve replacement becomes necessary. As in Mitral valve replacement, the prosthesis size is selected based on the diameter of the A-V ring sizing the anterior leaflet. The size of the ventricular cavity is also noted. ${ }^{30}$

\section{List of Abbreviations}

A-V- Atrioventricular, AL- Length of anterior leaflet. PLLength of posterior leaflet. SL- Length of septal leaflet. AHHeight of anterior leaflet. $\mathrm{PH}-\mathrm{Height}$ of posterior leaflet. $\mathrm{SH}-$ Height of septal leaflet, TR- Tricuspid regurgitation, ASAnteroseptal, PS- Posteroseptal.

\section{CONCLUSIONS}

We hope that the data derived from our study would help in better understanding the anatomy of the tricuspid valve complex in south Indian population. It would serve as a baseline data for cardiologists, cardiac surgeons in assessing the severity of tricuspid pathology, in planning appropriate surgery and in designing prosthetic heart valves of proper size.

\section{ACKNOWLEDGEMENT}

We thank Dr. Shana Baby, post graduate student in Anatomy for her timely help during the study.

\section{REFERENCES}

[1] Anderson RH, Spicer DE, Hlavacek AM, et al. Wilcox 's Surgical anatomy of the heart. $4^{\text {th }}$ edn. NewYork, USA: Cambridge University Press 2013: p. 52-72.

[2] Cohn LH. Tricuspid regurgitation secondary to mitral valve disease: when and how to repair. J Card Surg 1994;9(Suppl 2):237-41.

[3] Dreyfus GD, Corbi PJ, Chan KM, et al. Secondary tricuspid or dilatation: which should be the criteria for surgical repair? Ann Thorac Surg 2005;79(1):127-32.

[4] Sellke FW, Marc R. Atlas of cardiac surgical techniques. Saunders Elsevier 2010: p. 246-62.

[5] Fukuda S, Saracino G, Matsumara Y, et al. Three dimensional geometry of the tricuspid annulus in healthy subjects and in patients with functional tricuspid regurgitation: a real-time, 3-dimensional echocardiographic study. Circulation 2006;114(Suppl 1):1492-8.

[6] Anwar AM, Geleijnse ML, Soliman OI, et al. Assessment of normal tricuspid valve anatomy in adults by realtime three-dimensional echocardiography. Int J Cardiovasc Imaging 2007;23(6):717-24.

[7] Perloff JK, Roberts WC. The mitral apparatus. Functional anatomy of mitral regurgitation. Circulation 1972;46(2):227-39.

[8] Standring S. Gray's Anatomy. 41 $1^{\text {st }}$ edn. London: Churchill Livingstone/ Elsevier 2016: p. 1003-4.

[9] Neeta KV. Clinical anatomy (A Problem Solving Approach) Vol. 1. $3^{\text {rd }}$ edn. New Delhi: Jaypee Brothers Medical Publishers 2016: p. 432-3.

[10] Dutta AK. Essentials of human anatomy. Part 1. $9^{\text {th }}$ edn. Kolkata: Current Books International 2013: p. 61-9.

[11] Westaby S, Karp RB, Blackstone EH, et al. Adult human valve dimensions and their surgical significance. Am J Cardiol 1984;53(4):552-6.

[12] Kalyani R, Thej MJ, Prabhakar K, et al. Morphometric analysis of tricuspid valve: an Indian perspective. J Nat Sci Biol Med 2012;3(2):147-51.

[13] Motabagani MAB. Comparative anatomical morphometric and histological studies of the tricuspid valve complex in human and some mammalian hearts. Journal of the Anatomical Society of India 2006;55(1):1-23.

[14] Silver MD, Lam JH, Ranganathan N, et al. Morphology of the Human tricuspid valve. Circulation 1971;43(3):333-48.

[15] Antoniali F, Braile DM, Poterio GM, et al. Tricuspid valve repair using the proportion between segments of normal tricuspid annulus as a parameter for annuloplasty. Rev Bras Cir Cardiovasc 2007;22(4):3939. 
[16] Skwarek M, Hreczecha J, Dudziak M, et al. The morphology of the right atrioventricular valve in the adult human heart. Folia Morphol (Warsz) 2006;65(3):200-8.

[17] Sairanen H, Louhino I. Dimensions of the heart and great vessels in normal children. A postmortem study of cardiac ventricles, valves and great vessels. Scand J Thorac Cardiovasc Surg 1992;26(2):83-92.

[18] Anwar MA, Geleijnse ML, Cate TFJ, et al. Assessment of tricuspid valve annulus size, shape and function using real-time three diamensional echocardiography. Int Cardiovasc Thorac Surg 2006;5(6):683-7.

[19] Rohilla A, Singh K, Rohilla J, et al. Tricuspid valve morphometry: a new learning from cadavers. Anat Physiol 2015;5(4):185.

[20] Yuh DD, Vricella LA, Yang SC, et al. John Hopkins Textbook of Cardiothoracic Surgery. Tricuspid valve disease. 2nd edn. New York: McGraw-Hill Medical Publisher 2014: p. 570-9.

[21] Rogers JH, Bolling SF. The tricuspid valve: current perspective and evolving management of tricuspid regurgitation. Circulation 2009;119(20):2718-25.

[22] Tang GH, David TE, Singh SK, et al. Tricuspid valve repair with an annuloplasty ring results in improved long-term outcomes. Circulation 2006;114(Suppl 1):I577-I-81.
[23] Shah PM. Hurst's The Heart. Tricuspid valve, pulmonary valve and multivalvular disease. $13^{\text {th }}$ edn. New York: McGraw-Hill Medical Publisher 2001: p. 1748.

[24] Deloche A, Guerinon J, Fabiani JN, et al. Anatomical study of rheumatic tricuspid valve diseases: application to the study of various valvuloplasties. Ann Chir Thorac Cardiovasc 1973;12(4):343-9.

[25] Ewy G. Tricuspid valve disease. In: Alpert JS, Dalen JE, Rahimtoola SH, eds. Valvular Heart Disease. $3^{\text {rd }}$ edn. Philadelphia, PA: Lippincott Williams \& Wilkins 2000: p. 377-92.

[26] Yiwu L, Yingchun C, Jianqun Z, et al. Exact quantitative selective annuloplasty of the tricuspid valve. J Thorac Cardiovasc Surg 2001;122(3):611-14.

[27] Braunwald NS, Ross J Jr, Morrow AG. Conservative management of TR in patients undergoing mitral valve replacement. Circulation 1976;35(Suppl 4):I63-9.

[28] Antunes M, Barlow JB. Management of tricuspid valve regurgitation. Heart 2007;93(2):271-6.

[29] Frederick GL, Michael MJ, Master techniques in cardiac surgery. Philadelphia: Wolters Kluwer 2016: p. 253-61.

[30] Abbas A, Jonathan CM. Khonsari 's Cardiac Surgery. $5^{\text {th }}$ edn. Philadelphia: Wolters Kluwer Health 2017: p. 11623. 